\title{
Systems Development Methods and Usability in Norway: An Industrial Perspective
}

\author{
Bendik Bygstad $^{1}$, Gheorghita Ghinea ${ }^{1,2}$, and Eivind Brevik ${ }^{1}$ \\ ${ }^{1}$ Norwegian School of Information Technology, Oslo, Norway \\ ${ }^{2}$ School of Information Systems and Computing, Brunel University, UK \\ bygen@nith.no, george.ghinea@brunel.ac.uk, eivind.brevik@nith.no
}

\begin{abstract}
This paper investigates the relationship between traditional systems development methodologies and usability, through a survey of 78 Norwegian IT companies. Building on previous research we proposed two hypotheses; (1) that software companies will generally pay lip service to usability, but do not prioritize it in industrial projects, and (2) that systems development methods and usability are perceived as not being integrated. We find support for both hypotheses. Thus, the use of systems development methods is fairly stable, confirming earlier research. Most companies do not use a formal method, and of those who do, the majority use their own method. Generally, the use of methods is rather pragmatic: Companies that do not use formal methods report that they use elements from such methods. Further, companies that use their own method import elements from standardised methods into their own.
\end{abstract}

\section{Introduction}

This paper investigates the relationship between two important disciplines of modern systems development; the use of systems development methods and the concepts and techniques of usability.

Systems development methods (SDM) have been in use the past forty years and constitute a core part of modern software engineering. Still, they represent a thorny issue, both because their effectiveness has been challenged [6], [15] and because of the continuous wars between proponents of different methods [10]. During the 1990s most methods became iterative and incremental, acknowledging the emergent nature of software development. Well-known examples are Rational Unified Process [8], DSDM [14], Microsoft Solutions Framework [11] and XP [1].

Usability, on the other hand, emerged during the late 1980s, and was embraced in the 1990s by parts of the software industry as a response to the challenges that web based software put on developers. The body of knowledge of usability is large and includes various perspectives, from usability engineering [12] to more contextoriented approaches [2].

This paper investigates empirically, through a survey among Norwegian IT companies, the relationship between SDM and usability in current industry practice. We investigate which SDMs that are adopted, and to which degree the companies have 
adopted usability techniques. These findings are used to investigate our core assumption - that systems development and usability are both accepted as best practices in principle, but not yet integrated in a full process.

The paper is structured as follows. In section 2 we discuss findings in earlier research, and present our two hypotheses. Then, in section 3, we briefly present our research method. In section 4 the result of research will be presented followed by a discussion. Section 5 concludes and points to further research.

\section{Assumptions and Hypotheses}

Although SDMs and usability have some similarities (they are both applied disciplines, and they play important roles in systems development) their differences are much more obvious. While SDMs originated from systems engineering and software economics [13] in the late 1960s, usability was developed in the late 1980s and early 1990s from HCI research, cognitive psychology and phenomenology. While systems development was - with some notable exceptions - mainly concerned about the inner workings of the system, usability focused on the user. Thus, the role of the user is different; in systems development the user is a means to elicit requirements [8], while for usability work the users are the prime means for designing the system [7], [12].

Systems development theorists tend to play down these differences, arguing that usability may easily be integrated into the formal frameworks [9]. Oppositely, usability researchers have argued that these differences add up to two different cultures of systems development, and have called for new approaches to counter the basically technical approach of SDMs. For example, Boivie et al [3] concluded - after a review of this relationship - somewhat pessimistically:

"We believe that one of the main difficulties with incorporating User Centric Systems Development in existing processes is that it requires a great deal more than simply adding a few activities to existing processes. It requires new development approaches, new methods, new roles, new ways of planning and allocating resources etc. Moreover, a usercentered approach changes the relationship between the user/client organization and the development organization (..)".

Our point of departure is that these issues should be investigated in an industrial context. From this discussion we propose two hypotheses. The first is concerned with the general status of usability in systems development.

H1: Software companies will generally pay lip service to usability, but do not prioritize it in industrial projects.

This hypothesis assumes that there is a gap between intention and reality; that the companies will express concern for usability, but not be willing to use resources on it in industrial projects with strong time and cost pressures.

The second hypothesis is concerned with the perceived relationship between systems development methods and usability. We assume that most companies use some kind of method and that they also relate to usability issues. However, we do not believe these are integrated in the practices of the development projects. 
H2: Systems development methods and usability are perceived by practitioners as not being integrated

In the next section we outline how the hypotheses were investigated.

\section{Research Method}

This section will first give a description of the sampling and sampling design that has been used. Then research design and analysis of survey responses are determined.

\subsection{Sampling and Sampling Design}

The greatest sampling challenge in this type of research is to identify which companies that actually engage in systems development [6]. This study builds on similar studies done in Norway in 2002, 2003 and 2004 [4], [5], where a great deal of effort was put into establishing a population of Norwegian IT companies that engage in systems development. Ideally, all companies involved in software development in Norway should be defined as the population for this research. This includes general private companies and public organisations as well as professional companies within the IT sector.

Earlier studies showed, however, that response rates from general private and public companies were too low to be useful. Thus, the population was limited to IT companies in the following three different Norwegian industrial classification (IC) codes:

\section{System- and software consulting 7260001 IT consulting 7260003 IT services}

Our sample was collected from two sources. First it consists of the 194 companies that accepted to participate in 2003. Second, this was supplemented by 65 companies that participate as partners in NITH student development projects, which we knew were engaged in systems development. Of course, this sampling strategy puts some limitations on the implications of our findings, which we will return to in our discussion.

\subsection{Research Design}

A questionnaire was designed, with 5 questions on SDMs and 8 questions on usability. We also asked how many persons were engaged in systems development in the company.

The survey was implemented electronically by using the QuestBack system ${ }^{1}$. This system is based on e-mail distribution of a link to the actual survey and replies via a web browser on the Internet. The QuestBack system has an automatic reminder, which was scheduled once to those who had not responded after the request to participate in the survey was sent out. After about a four weeks' period, the survey was closed with 87 responses, representing a response rate of $33 \%$.

\footnotetext{
${ }^{1}$ www.questback.com
} 


\section{Results and Discussion}

This section presents the results and discussion, and is divided into three parts: (1) Adoption of SDM (2) Usability in requirements and testing and (3) The relationship between SDMs and usability. The first two sections are descriptive, while we test our hypotheses in part 3 .

\subsection{Adoption of SDM}

Respondents were asked whether or not they were using a formal SDM.

Table 1. Formal SDM use

\begin{tabular}{|l|c|c|}
\hline Answer & N & Percent \\
\hline Yes & 27 & $35 \%$ \\
\hline $\begin{array}{c}\text { We do not use a formal SDM, but we use a } \\
\text { number of techniques and tools }\end{array}$ & 45 & $57 \%$ \\
\hline No & 6 & $8 \%$ \\
\hline SUM & 78 & $100 \%$ \\
\hline
\end{tabular}

As shown in Table 1 the majority do not use a formal method, but a number of techniques and tools. Respondents that answered 'yes' were then asked to indicate which formal SDMs that were in use. The result is shown in Table 2.

Table 2. Breakdown of formal SDMs used in Norwegian companies

\begin{tabular}{|l|c|c|c|}
\hline Method & Use 2006 & Use 2003 & Use 2002 \\
\hline Own method & $\mathbf{6 8 \%}$ & $78 \%$ & $79 \%$ \\
\hline RUP & $\mathbf{2 9 \%}$ & $29 \%$ & $23 \%$ \\
\hline XP/Agile methods & $\mathbf{1 8 \%}$ & $21 \%$ & $17 \%$ \\
\hline MSF & $\mathbf{2 9 \%}$ & $19 \%$ & $21 \%$ \\
\hline OPEN & $\mathbf{0 \%}$ & $11 \%$ & $0 \%$ \\
\hline PSO & $\mathbf{0 \%}$ & $7 \%$ & $21 \%$ \\
\hline Other methods & $\mathbf{1 9 \%}$ & $10 \%$ & $13 \%$ \\
\hline
\end{tabular}

The sum of percentages is greater than $100 \%$ because some companies use more than one method. A large majority, $68 \%$, of software development companies uses their own method. This is in line with the findings for the 2003 and 2002 survey. The numbers do not provide evidence of a significant change in the usage of commercial methods. Rather, they suggest that companies tend to stick to a certain method, and are reluctant to change. The comments from the companies illustrate this point; they are generally quite satisfied with their choice of method. 


\subsection{Adoption of Usability Techniques}

Designing for usability typically involves establishing user requirements for a new system, iterative design and testing with representative users. Thus, in order to examine the interplay between usability and system development methods, in our survey we specifically sought to explore to which degree usability was included in the system requirements and the degree of usability testing. Usability in requirements was measured by two questions, the first being "When will you include usability in requirements?" The result is shown in Table 3.

Table 3. Usability and requirements

\begin{tabular}{|l|c|c|}
\hline Answer & N & Percent \\
\hline Always & 55 & $72 \%$ \\
\hline $\begin{array}{c}\text { Only if usability problems emerge during the } \\
\text { project }\end{array}$ & 8 & $10 \%$ \\
\hline Only if the customer demands it & 12 & $15 \%$ \\
\hline $\begin{array}{l}\text { Only if we have an internal usability specialist } \\
\text { available }\end{array}$ & 2 & $3 \%$ \\
\hline Sum & $\mathbf{7 7}$ & $\mathbf{1 0 0} \%$ \\
\hline
\end{tabular}

The second question was "How do you collect requirements for usability?" Results are shown in Table 4.

Table 4. Usability and requirements (multiple answers possible)

\begin{tabular}{|l|c|}
\hline Answer & Percent \\
\hline Interviewing users & $67 \%$ \\
\hline Best practice from earlier projects & $71 \%$ \\
\hline Books, Internet resources & $19 \%$ \\
\hline Other & $12 \%$ \\
\hline
\end{tabular}

Respondents were also asked two questions on usability testing. The first was "How many users are typically engaged in usability testing?" As Table 5 shows, the samples of users in testing are generally small, most being less than 10 users.

Table 5. Number of users involved in usability testing

\begin{tabular}{|l|c|}
\hline Answer & Percent \\
\hline 1 -10 users & $66 \%$ \\
\hline $11-50$ users & $21 \%$ \\
\hline More than 50 users & $3 \%$ \\
\hline We do not test usability & $10 \%$ \\
\hline Sum & $\mathbf{1 0 0} \%$ \\
\hline
\end{tabular}


Table 6 show how these users were selected. It shows that $40 \%$ of the respondents report that they select a representative sample of users.

Table 6. Selection criteria for users in usability testing

\begin{tabular}{|l|c|}
\hline Answer & Percent \\
\hline Arbitrary sample of users & $5 \%$ \\
\hline Representative sample of users & $40 \%$ \\
\hline Own employees & $9 \%$ \\
\hline Customer's employees & $23 \%$ \\
\hline Other & $15 \%$ \\
\hline Do not test usability & $8 \%$ \\
\hline Sum & $\mathbf{1 0 0} \%$ \\
\hline
\end{tabular}

Summarizing the findings on usability the results shows that the majority of the respondents include usability in their requirements, and that they also collect usability requirements by including users in the process (Table 3 and Table 4). In usability testing, however, the number of users seems quite small, as most of the companies only include less than 10 users (Table 5). Furthermore, only about $40 \%$ of the users selected for testing are a representative sample of the users.

\subsection{The Relationship Between SDM and Usability}

Returning to our two hypotheses we first assumed:

- H1: Software companies will generally pay lip service to usability, but not prioritize it in industrial projects.

To investigate this hypothesis we first assess the answers of two general questions on usability. The respondents were asked - in general terms - how important usability requirements and usability testing was for the success of their projects. The result is showed in Table 7.

Table 7. Usability requirements, usability testing - and project success

\begin{tabular}{|c|c|c|}
\hline Answer & $\begin{array}{c}\text { Usability } \\
\text { requirements }\end{array}$ & $\begin{array}{c}\text { Usability } \\
\text { Testing }\end{array}$ \\
\hline 6- Very important & $33 \%$ & $14 \%$ \\
\hline 5 & $38 \%$ & $23 \%$ \\
\hline 4 & $21 \%$ & $31 \%$ \\
\hline 3 & $6 \%$ & $19 \%$ \\
\hline 2 & $1 \%$ & $6 \%$ \\
\hline 1 - Quite unimportant & $1 \%$ & $5 \%$ \\
\hline Sum & $100 \%$ & $100 \%$ \\
\hline
\end{tabular}


As Table 7 shows the majority of the companies thinks usability is important for the success of their projects. Somewhat surprising, usability requirements are considered more important than usability testing.

However, when assessing the answers of the more concrete questions on usability activities in projects, the results show a different picture. Concerning usability requirements, $72 \%$ of the companies always include it, and almost $67 \%$ also interview the users, as showed in Table 4 and Table 5. On the other hand, only $40 \%$ of the companies use a representative sample of users for usability testing (Table 6). Further, the number of users engaged in usability testing is generally quite small, as showed in Table 5.

In concluding, we find that our first hypothesis is supported by our empirical materials. There is a gap between intention and reality: the companies express interest and concern for usability, but this stance is not corroborated by their subsequent responses, which reveal that they are less willing to use resources on it in industrial projects with strong time and cost pressures.

Our second hypothesis was:

- H2: Systems development methods and usability are perceived by practitioners as not being integrated

The respondents were asked "To which degree do you think that usability is integrated in your systems development method (whether you use a formal SDM or not)?" The result is shown below in Table 8 .

Table 8. To which degree is usability integrated in systems development method?

\begin{tabular}{|l|c|c|}
\hline \multicolumn{1}{|l|}{ Answer } & $\mathbf{N}$ & Percent \\
\hline 6- To a large degree & 11 & $14 \%$ \\
\hline 5 & 18 & $23 \%$ \\
\hline 4 & 21 & $26 \%$ \\
\hline 3 & 14 & $18 \%$ \\
\hline 2 & 10 & $13 \%$ \\
\hline $1-$ Not at all & 2 & $3 \%$ \\
\hline No answer & 2 & $3 \%$ \\
\hline Sum & $\mathbf{7 8}$ & $\mathbf{1 0 0} \%$ \\
\hline
\end{tabular}

How should this result be interpreted? When we correlate these findings with the adopted SDM we find no significant associations. It does not affect this profile whether the SDM is the company's own or a commercial method, neither if the company uses a formal SDM nor only a set of techniques.

We interpret this result as an indication that the two disciplines currently seem to live side by side. They are not integrated, neither are they perceived as contradictions. Thus, we find some support also for our second hypothesis.

Do these findings support the somewhat pessimistic view from several usability researchers [3], [7] that the two cultures are irreconcilable? We think the answer is no, for two reasons. First, we have documented that most IT companies do not view formal SDM as rigid frameworks; rather they pick and use elements that integrate with 
their existing work practices. This situation makes it much easier to also integrate usability work. The second reason is that the IT companies in this survey do view usability as a key factor for project success. What is lacking is probably a clearer role for usability work, as also suggested by Boivie et al [3].

\subsection{Limitations}

We acknowledge that there are limitations to this research. The 259 companies do not represent a random sample of the IT company population, which may bias our results. Regarding the questionnaire, one may question whether the respondents have the same understanding of the usability terms as in the IS research community. Further research should address these issues.

\section{Conclusions}

This paper investigated the adoption of systems development methods and usability, through a web based survey in the software industry in Norway. The significance of this research is that it extends earlier case study research on SDMs and usability, within an industrial perspective. Although our sample is not fully statistically controlled in relation to the population, we argue that it is large enough to justify the findings.

The point of departure was the assumption that two important practices in software development, one of traditional systems development methods and one of usability work, are not integrated in industrial software projects.

We find that the use of systems development methods is fairly stable in Norway, confirming earlier research. Most companies do not use a formal method, and of those who do, the majority uses their own method. Generally, the use of methods is rather pragmatic: The companies that do not use SDMs report that they use elements from such methods. Further, companies that use their own method import elements from standardised methods into their own.

We find support for our first hypothesis; that companies pay lip service to usability but do not prioritize it in development projects. This applies particularly to usability testing. We also find some support for our second hypothesis; that systems development methods and usability are perceived as not being integrated.

These finding do not, however, support a view of two cultures of systems development. Both the flexible approach to systems development practices and the generally positive attitudes to usability allow for a gradual integration of usability techniques into traditional systems development.

\section{References}

1. Beck, K.: Extreme Programming Explained: Embrace Change. Addison-Wesley, Boston (2000)

2. Beyer, H., Holzblatt, K.: Contextual design: A customer-centered approach to systems designs. Morgan Kaufman Publishers, San Francisco (1997)

3. Boivie, I., Gulliksen, J., Gøransson, B.: The lonesome cowboy: A study of the usability designer role in systems development. Interacting with Computers 18, 601-634 (2006) 
4. Bygstad, B., Fagerstrøm, A., Østensen, T.: Exploring the relationship between software development processes and IT based business innovation. A quantitative study in Norway. In: Proceedings of NOKOBIT 2004: Norsk konferanse for organisasjoners bruk av IT, Stavanger, Norway (2004)

5. Bygstad, B., Fagerstrøm, A., Østensen, T.: Vi bruker vår egen metode, og den fungerer utmerket. En unders $\emptyset$ kelse av hvilke utviklingsmetoder som er i bruk i norske programvareutviklingsmiljøer. In: Proceedings of NOKOBIT 2002: Norsk konferanse for organisasjoners bruk av IT: Kongsberg (November 25-27, 2002)

6. Fitzgerald, B.: An empirical investigation into the adoption of systems development methodologies. Information \& Management 34, 317-328 (1998)

7. Iivari, N.: 'Representing the User' in software development - a cultural analysis of usability work in the product development context. Interacting with Computers 18, 635-664 (2006)

8. Jacobson, I., Booch, G., Rumbaugh, R.: The Unified Software Development Process. Reading, Addison Wesley (1999)

9. Larman, C.: Agile and Iterative Development: A Manager's Guide. Addison-Wesley, Reading (2004)

10. Larman, C., Basili, V.R.: Iterative and Incremental Development: A Brief History. IEEE Computer 36(6), 47-56 (2003)

11. Microsoft, Microsoft Solutions Framework (2004)

12. Nielsen, J.: Usability Engineering. Academic Press, Boston, MA (1993)

13. Sommerville, I.: Software Engineering. Harlow, Pearson Education (2001)

14. Stapleton, J.: DSDM: Business Focused Development. Addison-Wesley, Harlow (2003)

15. Truex, D., Baskerville, R., Travis, J.: Amethodical systems development: the deferred meaning of systems development methods. Accounting, Management and Information Systems 10, 53-79 (2000) 